\title{
Spatial and temporal variation of trematode infection in coexisting populations of intertidal gastropods Littorina saxatilis and L. obtusata in the White Sea
}

\author{
A. I. Granovitch ${ }^{1, *}$, S. O. Sergievsky ${ }^{2}$, I. M. Sokolova ${ }^{2}$ \\ ${ }^{1}$ Dept of Invertebrate Zoology, St. Petersburg State University, 199034 St. Petersburg, Russia \\ ${ }^{2}$ White Sea Biological Station, Zoological Institute of the Russian Academy of Sciences, Universitetskaya nab., 1, \\ 199034 St. Petersburg, Russia
}

\begin{abstract}
Trematode infection was studied in sympatric populations of the periwinkles Littorina saxatilis and L. obtusata in 2 regions of Kandalaksha Bay of the White Sea to assess host-parasite interactions at the population level. Twenty-seven spatially separated populations were each surveyed in $1984-1994 ; 2$ heavily infected populations were investigated annually over a 16 yr period. Ten trematode species were found in the periwinkle populations. The closest association in spatial distribution and temporal dynamics was observed between 3 ecologically and morphologically similar trematodes of the 'pygmaeus' group: Microphallus piriformes, M. pygmaeus and M. pseudopygmaeus. For these 3 species, the prevalences were closely associated in the 2 host species when spatially separated sites from the 2 studied regions were considered, while in the 2 populations studied over the 16 yr period, a correlation was only observed between the infection levels of $L$. saxatilis and $L$. obtusata by either $M$. piriformes and immature microphallids. Likewise, within each host species, significant correlations were revealed between the prevalence of the different microphallids of the 'pygmaeus' groups. However, they were fewer and weaker when the long-term dynamics of infection in the 2 heavily infected populations were considered. Most other trematodes did not show significant association in prevalence either within or between the 2 host species on spatial and temporal scales.
\end{abstract}

KEY WORDS: Spatial distribution - Long-term dynamics - Trematode infection - Littorina spp. White Sea

\section{INTRODUCTION}

Host-parasite interactions on the population level have recently come into focus of research on coastal ecosystems (Lauckner 1983, 1984, Jokela \& Lively 1995, Curtis 1996, Abdul-Salam et al. 1997, Mouritsen 1997). Parasites are recognized as important members of communities influencing abundance and structure of their host populations (Galaktionov \& Dobrovolsky

\footnotetext{
- Present address: Dept of Invertebrate Zoology, Faculty of Biology and Soil Sciences, Universitetskaya nab., 7/9, 199034 St. Petersburg, Russia.

E-mail: andrey@ag2304.spb.edu
}

1984, Granovitch 1992, Lafferty 1993) and are included in food chains (Lauckner 1983, 1984). Interaction of populations of a parasite with the host populations is complicated and can include multiple 'vertical' and 'horizontal' links. In general, the whole system of interacting populations of a parasite and hosts (which was termed a parasitic system by Beklemishev 1970) includes host populations in which subsequent stages of the life cycle of the parasite develop. Different hosts housing subsequent life cycle stages of the parasite are termed metaxenic hosts (Granovitch 1996, Galaktionov \& Dobrovolsky 1998). For example, the molluscs, the fish and the bird providing development of sporocistae and rediae, metacercariae and adult hermaphrodite 
individuals of the trematode Cryptocotyle lingua, respectively, are metaxenic hosts for this parasite. In addition, some life cycle stages of the parasite may infect different host species. Such 'parallel' host species housing the same developmental stage of a parasite are called paraxenic hosts (Granovitch 1996, Galaktionov \& Dobrovolsky 1998). The range of paraxenic hosts reflects the specificity of a parasite. An example of paraxenic hosts for a trematode, Microphallus pygmaeus, may be the molluscs Littorina saxatilis, L. obtusata, L. littorea, and L. fabalis, which all may host sporocystae of this parasite.

Recently many studies have dealt with the role of parasites in natural communities and yielded important data about the structure of natural parasitic systems and the potential regulatory mechanisms providing stability to these systems (Lauckner 1984, 1986 , Shostak \& Dick 1989, Reversat \& Silan 1991). However, detailed data about the distribution of parasites in host populations and the population aspects of host-parasite interactions are still scarce.

Intertidal snails of the genus Littorina and their trematode parasites are a convenient model for investigation of different aspects of structure and functioning of a parasitic system. In the White Sea intertidal zone, the periwinkles Littorina saxatilis and L. obtusata form highly abundant coexisting settlements. These snails serve as first intermediate hosts for 10 trematode species (Granovitch 1992). The species list of trematode parasites was found to be identical for White Sea L. saxatilis and L. obtusata (Sergievsky et al. 1997).

We studied trematode distribution and infection prevalence in 2 regions of Kandalaksha Bay of the White Sea: (1) to make a quantitative estimation of degree of paraxenic usage of populations of several host species by the same developmental stage of a parasite; (2) to investigate the interaction of the same host population with several species of parasites.
According to the terminology of Bush et al. (1997), this is a study of a component population of parasites (1) and of component communities (2) as structural entities of a suprapopulation or a supracommunity, respectively. We also performed a long-term monitoring study of population structure and prevalence in coexisting Littorina saxatilis and L. obtusata populations from 2 sites with high infection levels (Sergievsky et al. 1997) to estimate the degree of longterm stability of the host-parasite interaction. This will provide us with a better insight into important aspects of host-parasite interactions on population and community levels.

\section{MATERIALS AND METHODS}

Host species. The prosobranchs Littorina obtusata and $L$. saxatilis are abundant species found in the intertidal zone of North Atlantic and Arctic shores (Matveeva 1974, Raffaelli 1982). Spatial distribution of the periwinkles in the White Sea intertidal zone differs in vertical zonation. In general, L. saxatilis inhabits higher intertidal horizons compared to L. obtusata. However, distributions of these 2 species overlap in the middle littoral, in the belt of brown macroalgae (predominantly Fucus vesiculosus). Substrate preferences of the periwinkles are also different. $L$. obtusata is almost exclusively found on brown macrophytes, whereas $L$. saxatilis inhabits boulders and gravel patches (Granovitch et al. 1987). In general, sympatric settlements of the 2 species of periwinkles are confined to the brown macroalgae belt in the mid-intertidal zone.

The periwinkles are dioecious. Longevity of Littorina obtusata in the White Sea is 8 to $11 \mathrm{yr}$, and that of $L$. saxatilis 7 to 9 yr (Granovitch et al. 1987). L. obtusata becomes mature at 3 to 4 yr old; age of maturation of L. saxatilis is 2 to 3 yr (Granovitch \& Sergievsky 1990).

Table 1 Trematode species found in Littorina saxatilis and L. obtusata populations in Kandalaksha Bay of the White Sea

\begin{tabular}{|c|c|c|c|c|c|}
\hline Family & Species ${ }^{*}$ & $\begin{array}{l}\text { Abbre- } \\
\text { viation }\end{array}$ & $\begin{array}{l}\text { 1st intermediate } \\
\text { hosts }\end{array}$ & $\begin{array}{l}\text { 2nd intermediate } \\
\text { hosts }\end{array}$ & Final hosts \\
\hline Microphallidae & Microphallus piriformes & PIR & Intertidal gastropods & No & Gulls, ducks \\
\hline Microphallidae & M. pygmaeus & PYG & Intertidal gastropods & No & Gulls, ducks \\
\hline Microphallidae & $M$. pseudopygmaeus & PSE & Intertidal gastropods & No & Gulls, ducks (?) \\
\hline Microphallidae & M. triangulatus & TRI & Intertidal gastropods & No & Birds \\
\hline Microphallidae & $M$. similis & SIM & Intertidal gastropods & Intertidal crustaceans & Gulls \\
\hline Opecoelidae & Podocotyle atomon & POD & Intertidal gastropods & Intertidal crustaceans & Fishes \\
\hline Echinostomatidae & Himasthla sp. & HIM & Intertidal gastropods & Intertidal bivalves & Birds \\
\hline Renicolidae & Renicola sp. & REN & Intertidal gastropods & Intertidal bivalves & Birds \\
\hline Notocotylidae & Notocotylus sp. & NOT & Intertidal gastropods & No & Birds \\
\hline Heterophyidae & Cryptocotyle sp. & CRY & Intertidal gastropods & Fishes & Gulls \\
\hline
\end{tabular}


Fertilization is internal. Both species of periwinkles have no free larval stage. L. obtusata lays benthic egg masses, and $L$. saxatilis is an ovoviviparous species (Matveeva 1974). The mobility of adults is low (1 to $3 \mathrm{~m}$ ) (Janson 1983); the progeny very likely remain in the 'parental' local population.

In the White Sea, Littorina saxatilis and L. obtusata are intermediate hosts of 10 trematode species belonging to 6 families (Mikhailova et al. 1988, Sergievsky et al. 1997) (Table 1).

Study sites. In the period 1982 to 1997 we surveyed Littorina saxatilis and $L$. obtusata populations from more than 50 sites in Chupa Inlet (subarctic region) and North Archipelago (arctic region) areas in the Kandalaksha Bay of the White Sea (Fig. 1), which are separated by over $100 \mathrm{~km}$. For this study we chose only those sites where L. saxatilis and L. obtusata cooccurred. In total we used 27 populations of each species of periwinkles. Position of the study sites are shown on Fig. 2. In most locations, $L$. saxatilis and $L$. obtusata populations were sampled only once during the period from 1984 to 1994 . Additionally, a site with high prevalence was chosen in each of the 2 regions where the long-term surveys of the population structure of the 2 species were performed. At these sites, sampling was performed annually in August-September of 1982 to 1997 :

(1) North Archipelago region, West Spit of Ryazhkov Island $\left(67^{\circ} 00^{\prime} 12^{\prime \prime} \mathrm{N}, 32^{\circ} 34^{\prime} 36^{\prime \prime} \mathrm{E}\right)$. The study site is situated on moderately sheltered stony beach. Tidal range is 1.8 to $2.2 \mathrm{~m}$. The intertidal zone is covered by boulders and stones, interspersed with gravel and sand. Brown macroalgae occupy the lower part of the intertidal zone, forming a belt 30 to $40 \mathrm{~m}$ wide. Ascophyllum nodosum and Fucus serratus are present in the lower part of the fucoid belt, whereas Fucus vesiculosus dominates in the upper part. In the horizon occupied by $A$. nodosum and in the lower part of the $F$. vesiculosus horizon, fucoids covered 90 to $100 \%$ of the area. In the upper part of the $F$. vesiculosus canopy, areas of fucoids altered with gravel and stone spots. In the lower intertidal horizon filamentous algae and blue mussel beds often occur. This vertical zonation was typical for this site during the study period, although the biomass of algae and mussels varied.

(2) Chupa Inlet, Korga Island (66 $6^{\circ} 18^{\prime} 54^{\prime \prime} \mathrm{N}, 33^{\circ} 57^{\prime}$ $06^{\prime \prime} \mathrm{E}$ ). This is a small sheltered islet totally submerged during high tide. In the central part of the islet, a large boulder (rock outlet) is surrounded by a gravel belt and then by a belt of brown macroalgae. Width of the fucoid canopy varied from 14 to $16 \mathrm{~m}$ over the $16 \mathrm{yr}$ period. Ascophyllum nodosum and Fucus vesiculosus are the dominant macrophyte species, and their vertical distribution is the same as on the West Spit of Ryazhkov Island (see above). Blue mussels Mytilus edulis do not form dense beds here; however, they are always present in the middle and lower intertidal zone.

Fig. 1. Positions of the study regions in the Kandalaksha Bay of the White Sea. A: North Archipelago; B: Chupa Inlet

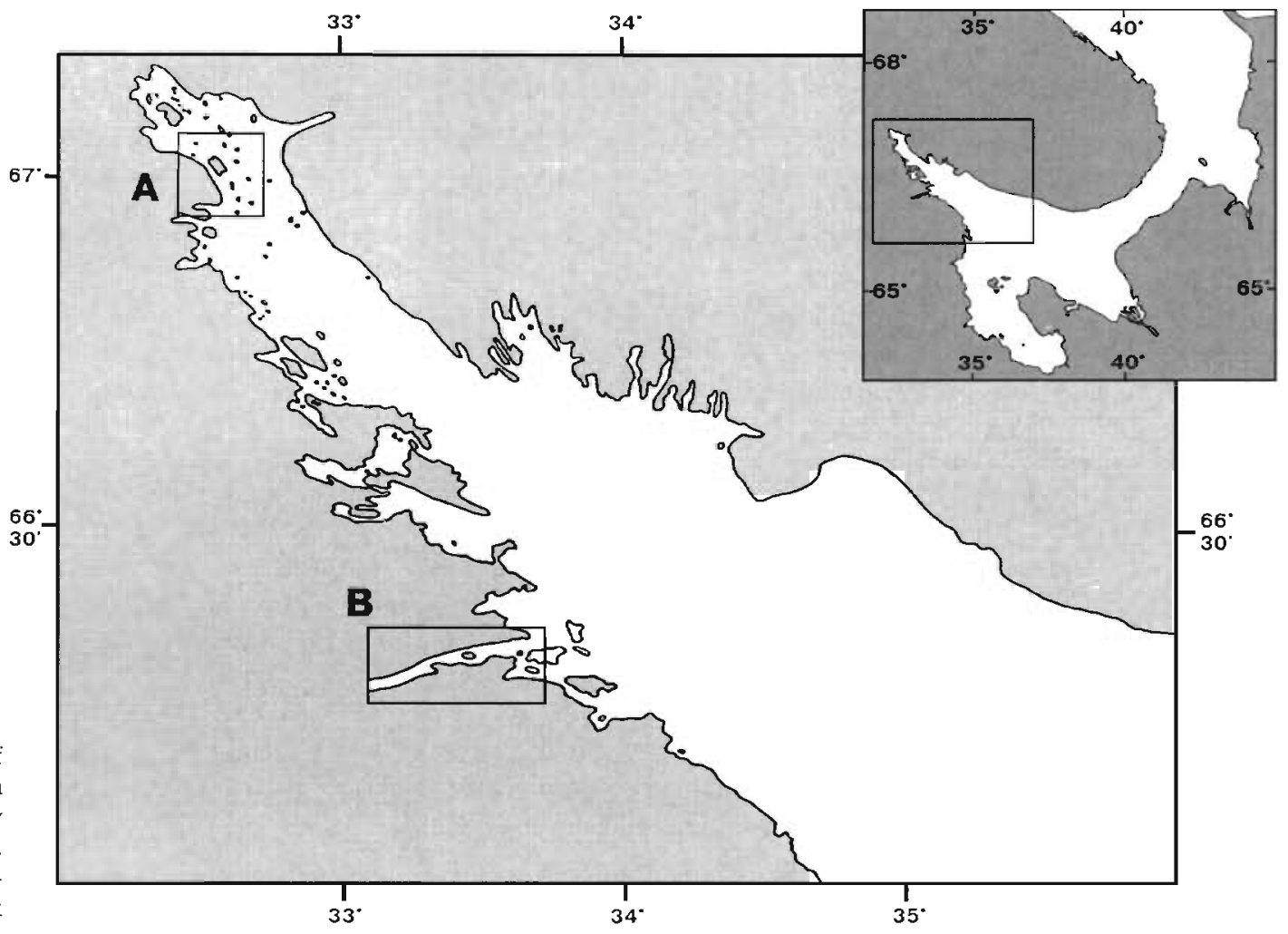




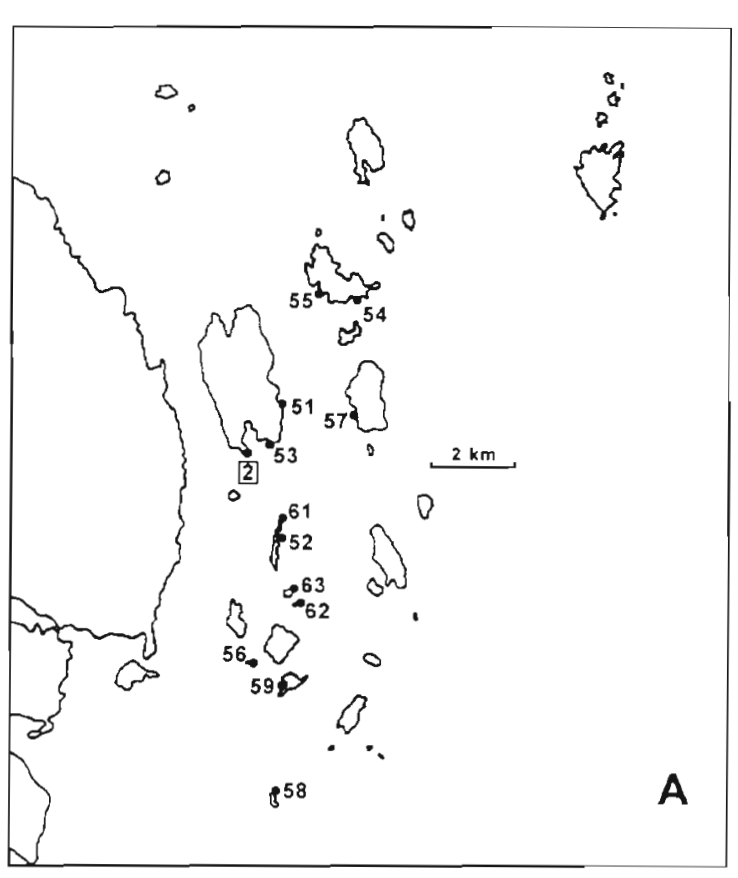

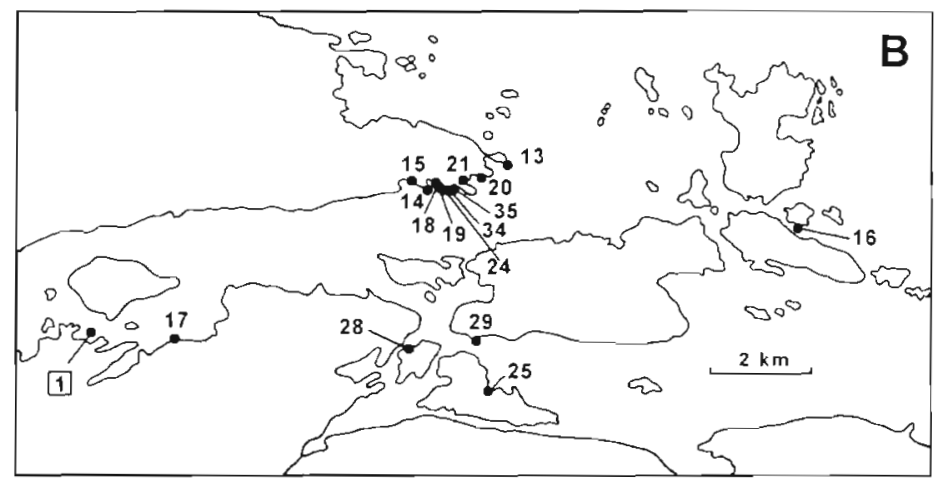

Fig. 2. Position of the study sites within the regions of the North Archipelago (A) and the Chupa Inlet (B). Numbers of the study sites as in Table 2. Site 1. Korga Island; Site 2: the West Spit of Rjazhkov Island
Sampling procedure. Random stratified sampling was performed in the fucoid belt (Bakus 1990). Samples were collected from a $1 / 40 \mathrm{~m}^{2}$ area. All seaweeds were cut off, taken together with the upper layer ( 2 to $3 \mathrm{~cm}$ in depth) of underlying sediment and placed into separate plastic bags. In the laboratory, samples were sieved through the soil sieve with $1 \mathrm{~mm}$ mesh size. All periwinkles were collected, shell diameter was measured and age of each mollusc determined by annual growth checks (which appear in spring when the growth is resumed after the winter stop). In very few cases age determination was difficult because of partial destruction of growth checks; these molluscs were placed into age groups according to their size. All snails greater than 1 yr of age were dissected using a binocular microscope to determine sex and to identify the species of trematode parasites (if present).

Statistical analyses. For comparison of infection prevalence of Littorina saxatilis and L. obtusata between the study regions, 2-way Model I Analysis of Variance was applied with fixed factors 'Host species' and 'Region'. Prior to analysis, the data were checked for the fit to normal distribution and for homogeneity of variances. Student-Neuman-Keuls test was used for post-hoc comparisons (Sokal \& Rohlf 1969). To test an association between the studied variables, Spearman's rank correlation was used. To avoid appearance of statistically significant side correlations due to the numerous zero values in the correlated variables, only those trematode species were included in the analysis which where found in not less than $1 / 3$ of the studied sites (for between-site comparisons) or not less then
8 yr out of 16 (for a long-term investigation in the 2 heavily infected populations). Sequential Bonferroni procedure was performed to correct probability levels for multiple comparisons (Rice 1989). However, as some authors argue against the use of corrections for multiply comparisons (Rothman 1990) because of the conservative nature of the respective tests and high probability of Type II error, we give data for both uncorrected and corrected significance levels. The sign test was applied for comparison of infection levels in sympatric populations of $L$. saxatilis and $L$. obtusata (Sokal \& Rohlf 1969).

\section{RESULTS}

\section{Species composition and general distribution pattern of trematodes}

Ten trematode species belonging to 6 families were found in the Littorina saxatilis and L. obtusata (Tables 1 to 4). In general, the species list of trematodes did not differ between the 2 host species. However, all 10 trematode species were found simultaneously in a host population only once, in 1984 in the L. saxatilis population from the West Spit of the Ryazhkov Island (Table $4 \mathrm{~B})$.

Infection prevalence varied considerably in the studied host populations. Out of $27 \mathrm{co}$-occurring settlements of the 2 host species, trematodes were not found in one population of Littorina saxatilis and in one population of L. obtusata, at different sites. In both cases, 
Table 2. Prevalence of different trematodes in 27 co-occurring populations of (A) Littorina obtusata and (B) L. saxatilis in the Kandalaksha Bay of the White Sea. Site numbers as in Fig. 2. NA: North Archipelago; CH: Chupa Inlet; IMM: immature sporocysts of microphallids. See Table 1 for other abbreviations of trematode species

\begin{tabular}{|c|c|c|c|c|c|c|c|c|c|c|c|c|c|c|}
\hline Site & Region & PIR & PYG & PSE & TRI & IMM & SIM & POD & HIM & CRY & NOT & REN & Total & No. of ind. \\
\hline \multicolumn{15}{|c|}{ (A) L. obtusata } \\
\hline 51 & NA & 1.9 & 2.8 & 1.6 & 0.0 & 0.6 & 0.0 & 0.3 & 0.0 & 0.0 & 0.0 & 0.0 & 7.2 & 320 \\
\hline 52 & NA & 9.9 & 2.0 & 1.3 & 0.0 & 6.6 & 0.0 & 1.3 & 0.0 & 0.7 & 0.0 & 0.0 & 21.9 & 151 \\
\hline 53 & NA & 7.9 & 5.0 & 4.0 & 0.0 & 0.0 & 0.0 & 1.0 & 0.0 & 1.0 & 0.0 & 0.0 & 18.8 & 101 \\
\hline 54 & NA & 0.0 & 6.7 & 2.2 & 0.0 & 2.2 & 0.0 & 0.0 & 0.0 & 0.0 & 0.0 & 0.0 & 11.1 & 45 \\
\hline 55 & NA & 10.2 & 6.1 & 0.0 & 0.0 & 0.0 & 0.0 & 0.0 & 0.0 & 0.0 & 0.0 & 0.0 & 16.3 & 49 \\
\hline 56 & NA & 16.1 & 5.4 & 1.8 & 0.0 & 0.0 & 0.0 & 0.0 & 0.0 & 0.0 & 0.0 & 0.0 & 21.4 & 56 \\
\hline 57 & NA & 4.8 & 9.5 & 2.4 & 0.0 & 4.8 & 0.0 & 0.0 & 2.4 & 0.0 & 0.0 & 0.0 & 23.8 & 42 \\
\hline 58 & NA & 10.0 & 5.0 & 35.0 & 0.0 & 0.0 & 0.0 & 0.0 & 0.0 & 0.0 & 0.0 & 0.0 & 45.0 & 20 \\
\hline 59 & $\mathrm{NA}$ & 15.0 & 5.0 & 25.0 & 0.0 & 0.0 & 0.0 & 0.0 & 0.0 & 0.0 & 0.0 & 0.0 & 40.0 & 20 \\
\hline 61 & NA & 3.8 & 0.9 & 0.9 & 0.0 & 0.0 & 0.0 & 0.0 & 0.0 & 0.0 & 0.0 & 0.0 & 6.6 & 106 \\
\hline 62 & NA & 14.3 & 3.2 & 1.6 & 0.0 & 0.0 & 0.0 & 1.6 & 1.6 & 0.0 & 0.0 & 0.0 & 23.8 & 63 \\
\hline 63 & NA & 2.0 & 4.1 & 0.0 & 0.0 & 0.0 & 0.0 & 0.0 & 0.0 & 0.0 & 0.0 & 0.0 & 6.1 & 49 \\
\hline 13 & $\mathrm{CH}$ & 0.8 & 1.9 & 0.2 & 0.0 & 1.3 & 0.0 & 1.3 & 0.2 & 0.0 & 0.0 & 0.0 & 5.7 & 471 \\
\hline 14 & $\mathrm{CH}$ & 0.0 & 2.4 & 0.3 & 0.0 & 1.8 & 0.3 & 0.3 & 0.0 & 0.0 & 0.0 & 0.3 & 5.4 & 332 \\
\hline 15 & $\mathrm{CH}$ & 0.0 & 2.3 & 0.6 & 0.0 & 1.2 & 0.0 & 0.6 & 0.0 & 0.0 & 0.0 & 0.0 & 4.7 & 172 \\
\hline 16 & $\mathrm{CH}$ & 2.0 & 0.0 & 0.0 & 0.0 & 3.7 & 0.4 & 0.0 & 0.0 & 0.0 & 0.0 & 0.0 & 6.1 & 244 \\
\hline 17 & $\mathrm{CH}$ & 0.0 & 1.2 & 0.0 & 0.0 & 0.2 & 0.0 & 0.0 & 0.0 & 0.0 & 0.0 & 0.0 & 1.4 & 420 \\
\hline 18 & $\mathrm{CH}$ & 0.0 & 0.7 & 0.0 & 0.0 & 6.2 & 0.0 & 0.7 & 1.1 & 0.0 & 0.0 & 0.4 & 9.1 & 274 \\
\hline 19 & $\mathrm{CH}$ & 0.9 & 0.0 & 0.0 & 0.0 & 0.9 & 0.0 & 0.9 & 0.0 & 0.0 & 0.0 & 0.0 & 2.6 & 117 \\
\hline 20 & $\mathrm{CH}$ & 0.8 & 0.8 & 0.0 & 0.0 & 0.8 & 0.0 & 0.0 & 0.0 & 0.0 & 0.0 & 0.0 & 2.4 & 126 \\
\hline 21 & $\mathrm{CH}$ & 0.0 & 0.0 & 0.0 & 0.0 & 2.6 & 0.0 & 0.7 & 0.0 & 0.0 & 0.0 & 0.0 & 3.4 & 267 \\
\hline 24 & $\mathrm{CH}$ & 2.5 & 0.6 & 0.0 & 0.0 & 0.0 & 0.0 & 0.6 & 0.0 & 0.0 & 0.0 & 0.0 & 3.8 & 314 \\
\hline 25 & $\mathrm{CH}$ & 1.4 & 0.0 & 0.0 & 0.0 & 0.0 & 0.0 & 0.0 & 0.0 & 0.0 & 0.0 & 0.0 & 1.4 & 69 \\
\hline 28 & $\mathrm{CH}$ & 0.0 & 0.0 & 0.0 & 0.0 & 0.0 & 0.0 & 6.7 & 0.0 & 0.0 & 0.0 & 0.0 & 6.7 & 15 \\
\hline 29 & $\mathrm{CH}$ & 0.0 & 0.0 & 0.0 & 0.0 & 0.0 & 0.0 & 0.0 & 0.0 & 0.0 & 0.0 & 0.0 & 0.0 & 14 \\
\hline 34 & $\mathrm{CH}$ & 0.0 & 3.9 & 0.0 & 0.0 & 0.0 & 0.0 & 0.0 & 1.3 & 0.0 & 0.0 & 0.0 & 5.2 & 77 \\
\hline 35 & $\mathrm{CH}$ & 0.0 & 1.0 & 0.0 & 0.0 & 0.0 & 1.0 & 0.0 & 0.0 & 0.0 & 0.0 & 0.0 & 2.0 & 98 \\
\hline \multicolumn{15}{|c|}{ (B) L. saxatilis } \\
\hline 51 & NA & 3.0 & 3.0 & 7.6 & 1.5 & 0.5 & 0.0 & 1.0 & 0.0 & 0.0 & 0.0 & 0.0 & 15.2 & 197 \\
\hline 52 & NA & 27.1 & 2.9 & 0.5 & 0.0 & 10.6 & 0.0 & 1.0 & 1.4 & 1.9 & 0.0 & 0.0 & 43.5 & 207 \\
\hline 53 & $\mathrm{NA}$ & 10.3 & 0.6 & 0.6 & 0.6 & 1.3 & 0.0 & 1.3 & 0.0 & 0.6 & 0.0 & 0.0 & 14.5 & 155 \\
\hline 54 & NA & 8.0 & 0.0 & 0.0 & 0.0 & 0.0 & 0.0 & 12.0 & 0.0 & 4.0 & 0.0 & 0.0 & 24.0 & 25 \\
\hline 55 & $\mathrm{NA}$ & 10.6 & 4.5 & 0.0 & 0.0 & 1.5 & 0.0 & 3.0 & 0.0 & 0.0 & 0.0 & 0.0 & 19.7 & 66 \\
\hline 56 & $\mathrm{NA}$ & 27.3 & 9.1 & 2.3 & 0.0 & 6.8 & 0.0 & 0.0 & 0.0 & 0.0 & 0.0 & 0.0 & 47.7 & 44 \\
\hline 57 & NA & 10.8 & 5.4 & 8.1 & 0.0 & 0.0 & 0.0 & 5.4 & 0.0 & 0.0 & 0.0 & 0.0 & 27.7 & 38 \\
\hline 58 & $\mathrm{NA}$ & 8.5 & 8.5 & 12.0 & 4.3 & 12.8 & 0.0 & 8.5 & 0.0 & 0.0 & 0.0 & 0.0 & 42.6 & 47 \\
\hline 59 & $\mathrm{NA}$ & 25.9 & 0.0 & 14.8 & 3.7 & 3.7 & 0.0 & 0.0 & 0.0 & 0.0 & 0.0 & 0.0 & 44.4 & 21 \\
\hline 61 & $\mathrm{NA}$ & 4.2 & 5.6 & 12.5 & 0.0 & 4.2 & 0.0 & 1.4 & 0.0 & 0.0 & 0.0 & 0.0 & 26.4 & 72 \\
\hline 62 & $\mathrm{NA}$ & 24.5 & 3.8 & 3.8 & 0.0 & 0.0 & 0.0 & 1.9 & 0.0 & 1.9 & 0.0 & 0.0 & 34.0 & 53 \\
\hline 63 & NA & 1.9 & 0.0 & 1.9 & 0.0 & 1.9 & 0.0 & 0.0 & 0.0 & 0.0 & 0.0 & 0.0 & 5.6 & 54 \\
\hline 13 & $\mathrm{CH}$ & 3.7 & 3.7 & 0.0 & 0.0 & 0.0 & 0.0 & 1.8 & 0.0 & 0.0 & 0.0 & 0.0 & 9.2 & 109 \\
\hline 14 & $\mathrm{CH}$ & 0.6 & 3.8 & 0.0 & 0.0 & 15.2 & 0.0 & 0.6 & 0.0 & 0.0 & 0.0 & 0.6 & 20.9 & 158 \\
\hline 15 & $\mathrm{CH}$ & 0.0 & 1.0 & 1.0 & 0.0 & 4.2 & 0.0 & 3.1 & 0.0 & 0.0 & 0.0 & 1.0 & 10.4 & 96 \\
\hline 16 & $\mathrm{CH}$ & 0.0 & 1.3 & 0.0 & 0.0 & 9.3 & 0.0 & 5.3 & 0.0 & 0.0 & 0.0 & 1.3 & 16.0 & 75 \\
\hline 17 & $\mathrm{CH}$ & 0.0 & 0.0 & 0.0 & 0.0 & 0.6 & 0.0 & 0.0 & 0.0 & 0.0 & 0.0 & 0.0 & 0.6 & 176 \\
\hline 18 & $\mathrm{CH}$ & 0.0 & 0.0 & 0.0 & 0.0 & 2.2 & 0.0 & 4.4 & 0.0 & 0.0 & 0.0 & 0.0 & 6.7 & 45 \\
\hline 19 & $\mathrm{CH}$ & 0.0 & 0.0 & 0.0 & 0.0 & 0.0 & 0.0 & 10.3 & 0.0 & 0.0 & 0.0 & 0.0 & 10.3 & 29 \\
\hline 20 & $\mathrm{CH}$ & 0.0 & 0.0 & 0.0 & 0.0 & 4.8 & 0.0 & 4.8 & 0.0 & 0.0 & 0.0 & 0.0 & 9.5 & 21 \\
\hline 21 & $\mathrm{CH}$ & 0.0 & 0.0 & 0.0 & 0.0 & 0.0 & 0.0 & 0.0 & 0.0 & 0.0 & 0.0 & 0.0 & 0.0 & 33 \\
\hline 24 & $\mathrm{CH}$ & 1.1 & 0.0 & 0.0 & 0.0 & 0.0 & 0.0 & 3.4 & 0.0 & 0.0 & 0.0 & 0.0 & 4.6 & 174 \\
\hline 25 & $\mathrm{CH}$ & 0.4 & 0.0 & 0.0 & 0.0 & 0.0 & 0.0 & 0.0 & 0.0 & 0.0 & 0.0 & 0.0 & 2.3 & 259 \\
\hline 28 & $\mathrm{CH}$ & 0.3 & 0.0 & 0.0 & 0.0 & 0.0 & 0.0 & 1.4 & 0.0 & 0.0 & 0.0 & 0.0 & 1.7 & 288 \\
\hline 29 & $\mathrm{CH}$ & 0.0 & 0.0 & 0.0 & 0.0 & 0.0 & 0.0 & 1.3 & 0.0 & 0.0 & 0.0 & 0.0 & 1.3 & 80 \\
\hline 34 & $\mathrm{CH}$ & 0.0 & 1.3 & 0.0 & 0.0 & 0.0 & 0.0 & 3.8 & 0.0 & 0.0 & 0.0 & 0.0 & 5.1 & 79 \\
\hline 35 & $\mathrm{CH}$ & 0.0 & 0.0 & 0.0 & 0.0 & 0.0 & 0.0 & 5.3 & 0.0 & 0.0 & 0.0 & 0.0 & 5.3 & 57 \\
\hline
\end{tabular}


Table 3. Long-term dynamics of prevalence of different trematodes in co-occurring populations of (A) Littorina obtusata and (B) L. saxatilis on Korga Island (Kandalaksha Bay of the White Sea). IMM: immature sporocysts of microphallids. See Table 1 for other abbreviations of trematode species

\begin{tabular}{|c|c|c|c|c|c|c|c|c|c|c|c|c|c|}
\hline Year & PIR & PYG & PSE & TRI & IMM & SIM & CRY & POD & HIM & NOT & REN & Total & No. of ind. \\
\hline \multicolumn{14}{|c|}{ (A) L. obtusata } \\
\hline 1982 & 9.2 & 0.6 & 0.0 & 0.0 & 2.4 & 1.5 & 0.0 & 0.6 & 0.6 & 0.0 & 0.4 & 15.0 & 533 \\
\hline 1983 & 8.9 & 0.7 & 0.2 & 0.0 & 2.8 & 0.5 & 0.1 & 0.2 & 0.1 & 0.0 & 0.3 & 13.8 & 913 \\
\hline 1984 & 17.0 & 0.0 & 0.0 & 0.0 & 1.4 & 0.3 & 0.0 & 0.3 & 0.7 & 0.0 & 0.3 & 20.1 & 294 \\
\hline 1985 & 7.1 & 1.4 & 0.0 & 0.0 & 1.8 & 0.4 & 0.0 & 0.0 & 0.7 & 0.0 & 0.4 & 11.3 & 283 \\
\hline 1986 & 15.8 & 7.2 & 0.0 & 0.0 & 3.3 & 0.0 & 0.0 & 0.0 & 0.0 & 0.0 & 0.0 & 26.3 & 152 \\
\hline 1987 & 17.2 & 2.1 & 0.0 & 0.0 & 7.3 & 3.4 & 0.4 & 0.0 & 0.0 & 0.0 & 0.0 & 29.6 & 233 \\
\hline 1988 & 15.6 & 2.1 & 0.0 & 0.0 & 9.9 & 1.4 & 0.7 & 0.7 & 0.7 & 0.0 & 0.0 & 31.2 & 141 \\
\hline 1989 & 16.1 & 3.2 & 0.0 & 0.8 & 2.4 & 3.2 & 0.0 & 0.8 & 0.0 & 0.0 & 0.0 & 26.6 & 124 \\
\hline 1990 & 12.1 & 2.9 & 0.3 & 0.0 & 1.4 & 0.0 & 0.0 & 0.3 & 0.0 & 0.0 & 0.0 & 17.0 & 347 \\
\hline 1991 & 25.3 & 3.8 & 0.3 & 0.3 & 2.1 & 0.9 & 0.0 & 0.6 & 0.6 & 0.0 & 0.0 & 33.2 & 340 \\
\hline 1992 & 22.3 & 4.0 & 0.4 & 0.4 & 4.0 & 0.4 & 0.4 & 1.1 & 1.4 & 0.0 & 0.0 & 33.8 & 278 \\
\hline 1993 & 25.0 & 1.5 & 0.0 & 1.0 & 8.0 & 2.0 & 0.0 & 0.0 & 2.5 & 0.0 & 1.0 & 39.0 & 200 \\
\hline 1994 & 28.0 & 4.7 & 2.5 & 0.0 & 4.2 & 0.8 & 0.4 & 0.4 & 0.8 & 0.0 & 0.0 & 39.0 & 236 \\
\hline 1995 & 17.5 & 8.1 & 0.0 & 0.0 & 8.5 & 0.9 & 0.4 & 0.4 & 0.4 & 0.0 & 2.2 & 35.9 & 223 \\
\hline 1996 & 22.4 & 6.3 & 0.0 & 0.7 & 9.8 & 0.7 & 0.7 & 0.0 & 0.0 & 0.0 & 0.0 & 40.6 & 143 \\
\hline 1997 & 28.8 & 2.5 & 0.0 & 0.0 & 4.2 & 0.4 & 0.4 & 0.4 & 0.0 & 0.0 & 1.3 & 37.9 & 240 \\
\hline \multicolumn{14}{|c|}{ (B) L. saxatilis } \\
\hline 1982 & 14.3 & 1.4 & 0.0 & 0.0 & 6.5 & 0.0 & 0.3 & 0.3 & 1.4 & 0.0 & 0.0 & 22.9 & 293 \\
\hline 1983 & 19.3 & 1.6 & 0.9 & 0.0 & 5.1 & 0.4 & 0.6 & 0.9 & 0.6 & 0.0 & 0.3 & 28.6 & 704 \\
\hline 1984 & 35.8 & 2.6 & 0.6 & 0.0 & 2.9 & 1.0 & 0.0 & 1.3 & 0.6 & 0.0 & 0.0 & 43.1 & 313 \\
\hline 1985 & 20.5 & 1.3 & 0.0 & 0.3 & 6.4 & 0.8 & 0.3 & 0.3 & 0.8 & 0.0 & 0.0 & 29.6 & 375 \\
\hline 1986 & 33.5 & 3.8 & 0.0 & 0.0 & 4.9 & 0.0 & 0.0 & 0.5 & 2.7 & 0.0 & 0.5 & 43.4 & 182 \\
\hline 1987 & 34.9 & 3.6 & 0.6 & 0.0 & 10.7 & 1.2 & 0.0 & 3.0 & 0.0 & 0.0 & 0.0 & 50.3 & 169 \\
\hline 1988 & 37.6 & 1.2 & 0.0 & 0.0 & 20.0 & 1.8 & 0.0 & 1.8 & 1.8 & 0.0 & 0.6 & 62.4 & 170 \\
\hline 1989 & 31.3 & 4.5 & 0.5 & 0.0 & 4.0 & 2.0 & 2.0 & 0.5 & 0.0 & 0.0 & 0.5 & 43.3 & 201 \\
\hline 1990 & 45.9 & 6.5 & 0.0 & 0.0 & 4.9 & 1.1 & 1.6 & 1.6 & 2.2 & 0.0 & 0.5 & 58.9 & 185 \\
\hline 1991 & 47.0 & 8.4 & 3.6 & 0.0 & 3.6 & 0.0 & 1.2 & 0.0 & 1.2 & 0.0 & 0.0 & 57.8 & 83 \\
\hline 1992 & 36.7 & 1.7 & 0.0 & 0.0 & 1.7 & 0.0 & 0.8 & 0.8 & 2.5 & 0.0 & 0.0 & 41.7 & 120 \\
\hline 1993 & 60.0 & 6.3 & 0.0 & 1.3 & 3.8 & 5.0 & 2.5 & 0.0 & 0.0 & 0.0 & 0.0 & 70.0 & 80 \\
\hline 1994 & 55.5 & 3.9 & 4.7 & 0.8 & 7.8 & 0.8 & 1.6 & 0.8 & 0.0 & 0.0 & 0.0 & 69.5 & 128 \\
\hline 1995 & 49.7 & 10.5 & 1.3 & 0.7 & 16.3 & 0.7 & 0.0 & 0.7 & 2.6 & 0.0 & 1.3 & 75.8 & 153 \\
\hline 1996 & 43.1 & 4.6 & 2.8 & 0.0 & 9.2 & 0.0 & 0.9 & 0.9 & 0.0 & 0.0 & 0.0 & 58.7 & 109 \\
\hline 1997 & 54.5 & 3.0 & 0.6 & 0.0 & 7.9 & 0.6 & 0.6 & 0.6 & 0.0 & 0.0 & 0.0 & 64.2 & 165 \\
\hline
\end{tabular}

sample sizes were small (Table 2), Overall trematode infection prevalence varied from 0 to $75.8 \%$ in different $L$. saxatilis populations, and from 0 to $50.3 \%$ in $L$. obtusata.

Comparison of trematode infection levels in 2 regions of the Kandalaksha Bay of the White Sea showed that prevalence for the 2 host species was higher in the North Archipelago region compared to the Chupa Inlet. These between-regional contrasts reflected the drastic difference in occurrence of the microphallids of the 'pygmaeus' group (2-way ANOVA revealed significance of the factor 'Region': $F=48.08, \mathrm{df}=1$, $p=0.00001$, while there were no significant effects of the factor 'Host species' and the 2 factor interaction: $\mathrm{p}=$ 0.27 and $p=0.38$ respectively). In contrast, the prevalences of other trematode species were similar in the studied regions (2-way ANOVA: $F=0.03, \mathrm{df}=1, \mathrm{p}=$ 0.86 , for the factor 'Region' and $F=0.28, \mathrm{df}=1, \mathrm{p}=0.60$ for the 2 factor interaction). In this case, significant effect of the factor 'Host species' was found ( $F=10.78$, $\mathrm{df}=1, \mathrm{p}=0.0019$ ) with Littorina saxatilis having higher prevalence of these trematodes in the both regions.

In the 2 host species, maximum prevalence was due to invasion by 4 closely related microphallid species of the 'pygmaeus' group (Microphallus piriformes, $M$. pygmaeus, $M$. pseudopygmaeus and $M$. triangulatus), by immature sporocysts of these species, and by Podocotyle atomon (Tables 2 to 4). Levels of infection by other trematodes were low and never exceeded $5 \%$ in total. $M$. piriformes was the most abundant trematode species. Prevalence of this parasite may reach $60 \%$ in Littorina saxatilis populations (Korga Island, 1993) and $50.1 \%$ in L. obtusata (Ryazhkov Island, 1994). In general, intermediate to high infection levels (10 to $15 \%$ and more) were detected only in those host populations where $M$. piriformis was present, and there this 
Table 4. Long-term dynamics of prevalence of different trematodes in co-occurring populations of (A) Littorina obtusata and (B) L. saxatilis on the West Spit of Rjazhkov Island (Kandalaksha Bay of the White Sea). IMM: immature sporocysts of microphallids. See Table 1 for other abbreviations of trematode species

\begin{tabular}{|c|c|c|c|c|c|c|c|c|c|c|c|c|c|}
\hline Year & PIR & PYG & PSE & TRI & IMM & SIM & CRY & POD & HIM & NOT & REN & Total & No. of ind. \\
\hline \multicolumn{14}{|c|}{ (A) L. obtusata } \\
\hline 1982 & 8.4 & 4.7 & 4.1 & 0.9 & 6.6 & 0.0 & 0.0 & 0.3 & 1.9 & 0.0 & 0.3 & 24.4 & 320 \\
\hline 1983 & 25.5 & 4.9 & 1.5 & 0.2 & 9.6 & 0.0 & 0.1 & 0.3 & 0.8 & 0.0 & 0.0 & 42.2 & 1058 \\
\hline 1984 & 32.4 & 3.9 & 1.5 & 0.0 & 3.6 & 0.0 & 0.3 & 0.0 & 1.2 & 0.0 & 0.0 & 42.1 & 330 \\
\hline 1985 & 45.6 & 4.2 & 3.4 & 0.0 & 4.2 & 0.0 & 0.0 & 0.8 & 0.0 & 0.3 & 0.3 & 54.7 & 384 \\
\hline 1986 & 25.1 & 3.3 & 0.2 & 0.0 & 2.5 & 0.2 & 0.0 & 0.6 & 0.8 & 0.0 & 0.6 & 31.9 & 486 \\
\hline 1987 & 20.4 & 3.6 & 0.8 & 0.0 & 16.0 & 0.0 & 0.0 & 1.5 & 1.0 & 0.3 & 0.5 & 42.0 & 393 \\
\hline 1988 & 31.3 & 3.5 & 0.9 & 0.0 & 4.1 & 0.2 & 0.0 & 0.6 & 0.2 & 0.0 & 0.4 & 40.3 & 543 \\
\hline 1989 & 16.0 & 1.9 & 0.3 & 0.0 & 1.6 & 0.0 & 0.0 & 0.3 & 1.2 & 0.3 & 0.0 & 19.7 & 686 \\
\hline 1991 & 19.0 & 3.5 & 1.1 & 0.0 & 8.2 & 0.0 & 0.0 & 0.3 & 0.3 & 0.0 & 0.0 & 31.0 & 709 \\
\hline 1992 & 21.1 & 2.8 & 1.1 & 0.2 & 10.4 & 0.2 & 0.0 & 0.2 & 0.4 & 0.0 & 0.1 & 35.5 & 1233 \\
\hline 1993 & 38.4 & 4.9 & 0.5 & 0.0 & 6.5 & 0.2 & 0.0 & 0.5 & 0.5 & 0.2 & 0.2 & 49.8 & 617 \\
\hline 1994 & 50.1 & 3.7 & 2.6 & 0.2 & 5.6 & 0.4 & 0.2 & 0.4 & 2.4 & 0.0 & 0.2 & 61.3 & 465 \\
\hline 1995 & 37.3 & 2.8 & 1.2 & 0.0 & 6.8 & 0.6 & 0.0 & 0.6 & 3.1 & 0.0 & 0.6 & 50.3 & 322 \\
\hline 1996 & 31.3 & 5.2 & 1.7 & 0.4 & 7.5 & 0.0 & 0.0 & 0.4 & 1.9 & 0.0 & 0.9 & 44.6 & 464 \\
\hline 1997 & 26.6 & 2.6 & 1.8 & 0.0 & 5.4 & 0.0 & 0.0 & 0.3 & 1.6 & 0.0 & 0.2 & 37.2 & 624 \\
\hline \multicolumn{14}{|c|}{ (B) L. saxatilis } \\
\hline 1982 & 32.3 & 4.8 & 2.6 & 0.3 & 11.4 & 0.1 & 0.0 & 0.1 & 1.3 & 0.3 & 0.1 & 48.8 & 682 \\
\hline 1983 & 42.8 & 4.3 & 2.6 & 0.2 & 13.5 & 0.0 & 0.1 & 1.1 & 1.0 & 0.2 & 0.0 & 63.6 & 1261 \\
\hline 1984 & 45.2 & 3.5 & 0.6 & 0.1 & 5.3 & 0.1 & 0.3 & 0.9 & 1.6 & 0.4 & 0.1 & 56.5 & 694 \\
\hline 1985 & 42.7 & 1.6 & 1.3 & 0.1 & 5.4 & 0.0 & 0.0 & 0.3 & 1.2 & 0.8 & 0.0 & 50.9 & 758 \\
\hline 1986 & 29.8 & 1.7 & 1.4 & 0.3 & 7.1 & 0.2 & 0.0 & 1.1 & 1.5 & 0.3 & 0.0 & 41.7 & 647 \\
\hline 1987 & 21.7 & 3.3 & 1.4 & 0.2 & 19.6 & 0.0 & 0.0 & 0.2 & 1.0 & 0.0 & 0.0 & 46.1 & 516 \\
\hline 1988 & 32.7 & 1.8 & 0.7 & 0.4 & 6.6 & 0.0 & 0.1 & 0.5 & 0.7 & 0.0 & 0.1 & 42.7 & 836 \\
\hline 1989 & 35.6 & 1.8 & 0.7 & 0.3 & 8.0 & 0.1 & 0.0 & 0.7 & 2.1 & 0.0 & 0.1 & 46.9 & 725 \\
\hline 1991 & 32.6 & 3.6 & 0.7 & 0.5 & 10.5 & 0.0 & 0.5 & 1.4 & 2.3 & 0.0 & 0.2 & 50.3 & 439 \\
\hline 1992 & 39.0 & 3.2 & 0.9 & 0.2 & 9.4 & 00 & 0.0 & 0.5 & 2.5 & 02 & 0.2 & 52.8 & 4.36 \\
\hline 1993 & 45.6 & 2.4 & 0.3 & 0.3 & 10.9 & 0.0 & 0.0 & 0.3 & 1.5 & 0.0 & 0.0 & 59.6 & 329 \\
\hline 1994 & 48.7 & 1.9 & 1.1 & 0.4 & 12.9 & 0.2 & 0.0 & 0.2 & 4.4 & 0.0 & 0.0 & 65.4 & 567 \\
\hline 1995 & 39.3 & 2.6 & 2.6 & 0.2 & 12.6 & 0.2 & 0.0 & 0.9 & 3.4 & 0.0 & 0.2 & 56.8 & 643 \\
\hline 1996 & 32.6 & 3.6 & 1.3 & 0.3 & 14.6 & 0.0 & 0.1 & 0.9 & 2.4 & 0.1 & 0.1 & 51.1 & 669 \\
\hline 1997 & 35.1 & 2.1 & 1.1 & 0.2 & 7.5 & 0.0 & 0.0 & 0.8 & 1.3 & 0.0 & 0.0 & 46.2 & 522 \\
\hline
\end{tabular}

parasite accounted for most infections. Some trematode species were quite rare: $M$. similis, Cryptocotyle lingua, Notocotylus sp. and Renicola sp. were found in 5 or less out of 29 studied populations of either host species (Tables 2 to 4). Prevalence of these trematodes never exceeded $4 \%$.

A long-term study of trematode species composition was performed in populations of the 2 hosts at each of the 2 sites with high infection levels (Korga Island and West Spit of South Inlet of Ryazhkov Island). The characteristic relative abundance of different trematodes was maintained throughout the study period. Infection levels were the highest for the microphallids of the 'pygmaeus' group, with Microphallus piriformes being the most abundant species. Overall prevalence of the trematodes not belonging to the 'pygmaeus' species complex was below $5 \%$ during the entire study in the 2 sites. In some years these rare species were absent (Tables $3 \& 4$ ).

The long-term dynamics of the overall prevalence in the studied populations of the 2 host species was governed by changes of the invasion with Microphallus piriformis, and to a lesser extent with $M$. pygmaeus and immature microphallids of the 'pygmaeus' group. Variation in the level of $M$. piriformes infection ranged from 8 to $28.0 \%$ and from 8.4 to $50.1 \%$ in $L$. obtusata populations from Korga Island and West Spit of Ryazhkov Island, respectively. For Littorina saxatilis, respective ranges were 14.3 to $60.0 \%$ and 21.7 to $48.7 \%$ for populations from Korga Island and West Spit of Ryazhkov Island, respectively (Tables 3 \& 4, Fig. 3).

In Littorina saxatilis and L. obtusata populations from the West Spit of Ryazhkov Island, several peaks of the prevalence of $M$. piriformes were found followed by the periods of lower infection levels (Fig. 3A). In populations of the 2 host species from Korga Island there was a tendency for the prevalence of $M$. piriformis to increase throughout the study period. This tendency could be easily followed despite a few local minima in infection levels in some years (Fig. 3B). 

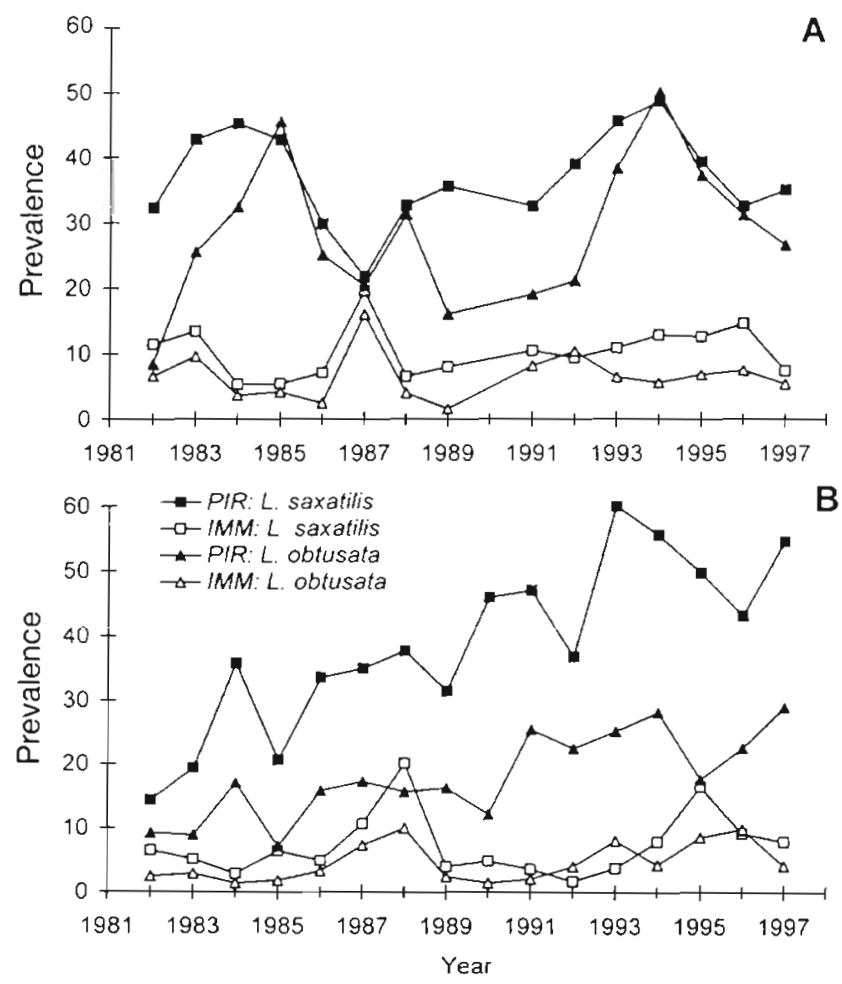

Fig. 3. Long-term dynamics of the prevalence of 2 host species (Littorina saxatilis and L obtusata) on the West Spit of (A) Rjazhkov Island and (B) Korga Island. PIR: Microphallus piriformis; IMM: immature sporocysts of microphallids

\section{Between-hosts comparison of infection prevalence and trematode distribution}

Comparison of average infection prevalence of the 2 groups of trematodes (the microphallids of the 'pygmaeus' group and the trematodes with free-living cercariae in the life cycle, see Table 1) showed that Littorina saxatilis populations were in general more heavily infected then $L$. obtusata from either region studied (Tables 2 to 4 ). This was true with respect to both specified groups of trematodes.

A special analysis was performed to compare infection prevalences specifically in pairs of coexisting populations of Littorina saxatilis and L. obtusata in spatial (using data on 27 spatially separated settlements) and temporal (using data of the long-term studies in the 2 sites) aspects. Because absolute values of infection prevalence varied drastically in different sites, we used a non-parametric sign test to check whether there was a systematic excess of infection level of one of the host species over the other in sympatric populations.

Overall prevalence was higher in Littorina saxatilis populations compared to the coexisting $L$. obtusata settlements $(\mathrm{p}=0.038$ for spatially separated populations; $\mathrm{p}=0.002$ and $\mathrm{p}=0.0002$ for long-term data for
West Spit of Ryazhkov Island and Korga Island, respectively). However, a sign test did not show any significant between-host differences when infection levels by separate trematode species were compared in $\mathrm{Co}-$ occurring $L$. saxatilis and L. obtusata populations in spatial scale.

In contrast, the dynamics of prevalence in the 2 heavily infected populations demonstrated that the infection level by Microphallus piriformes is consistently higher in Littorina saxatilis compared to L. obtusata $(p=0.01$ and $p=0.0002$ in settlements from West Spit of Ryazhkov Island and Korga Island, respectively). In the settlement from Korga Island, L. saxatilis showed a consistently higher level of infection by immature sporocysts of 'pygmaeus' group ( $p=0.002)$ and Himasthla $\mathrm{sp} .(\mathrm{p}=0.039)$ compared to $L$. obtusata during $16 \mathrm{yr}$ of the study. The analysis of long-term data in these 2 sites also revealed the only case of systematic excess of prevalence in L. obtusata over L. saxatilis populations when invasion by $M$. pygmaeus was considered $(p=0.039)$.

\section{Analysis of association between the occurrence of different trematode species in the two hosts}

We compared association between infection prevalence of different trematodes in the 2 host species to test if there was a tendency of correlated spatial or temporal change in the infection levels in populations of the 2 hosts.

There was a highly significant correlation between the infection prevalence of coexisting Littorina saxatilis and $L$. obtusata populations from spatially separated sites when the 4 species of the microphallids of 'pygmaeus' group were considered (Fig. 4A). Quite strong positive association $\left(\mathrm{r}_{\mathrm{s}}>0.66\right)$ was found between the occurrence of Microphallus piriformes and M. pseudopygmaeus in populations of the 2 hosts on spatial scale. Significant correlation $\left(r_{s}=0.69\right)$ was found between the infection prevalence of $M$. piriformes in L. saxatilis populations and that of $M$. pygmaeus in coexisting $L$. obtusata settlements. These correlations were statistically significant even when the sequential Bonferroni correction for multiple comparisons was applied (Fig. 4A).

Analysis of correlation between long-term changes of prevalence in Littorina saxatilis and L. obtusata populations showed that the infection levels by Microphallus pygmaeus $\left(\mathrm{r}_{\mathrm{s}}=0.62, \mathrm{p}=0.011\right), M$. piriformes $\left(\mathrm{r}_{\mathrm{s}}=0.81, \mathrm{p}=0.0002\right)$ and immature microphallids of 'pygmaeus' group $\left(r_{s}=0.66, p=0.005\right)$ changed concordantly in the 2 host species from Korga Island (Fig. 4C). There was also a trend to correlated longterm changes of infection by $M$. pygmaeus in $L$. sax- 


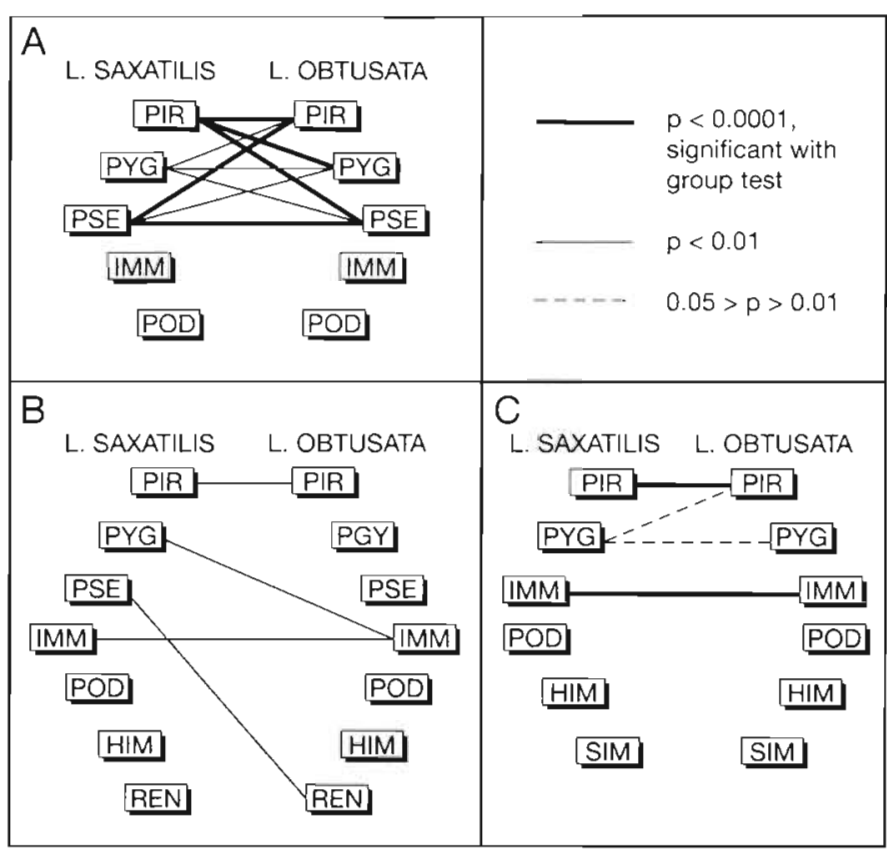

Fig. 4. Correlations of prevalence of different trematodes between the coexisting populations of the 2 host species (Littorina saxatilis and $L$. obtusata). Correlations in (A) 27 populations from spatially separated sites; (B) in the populations from the West Spit of Rjazhkov Island over the 16 yr study period; $(\mathrm{C})$ in the populations from the Korga Island over the 16 yr study period. IMM: immature sporocysts of microphallids. See Table 1 for other species abbreviations

atilis and that by $M$. piriformes in coexisting $L$. obtusata populations from this site.

In the settlement from West Spit of the Ryazhkov Island a significant positive association was found between the infection levels of the 2 host species for Microphallus piriformes $\left(r_{s}=0.72, p=0.003\right)$ and immature microphallid sporocysts $\left(\mathrm{r}_{\mathrm{s}}=0.74, \mathrm{p}=\right.$ $0.002)$. At this site, an agreement between long-term dynamics of prevalence were also detected: (1) for $M$. pygmaeus in Littorina saxatilis and immature microphallids in L. obtusata (Fig. 4B), and (2) for $M$. pseudopygmaeus in L. saxatilis and Renicola sp. in $L$. obtusata (Fig. 4B). After sequential Bonferroni correction no significant relationships could be detected between the long-term changes of prevalence of the populations of the 2 hosts from the West Spit of the Ryazhkov Island.

\section{Analysis of association between different trematodes in the populations of the same host species}

Examination of co-occurrence of different trematodes in spatially separated populations within each host species showed close positive association between prevalence of the microphallids of 'pygmaeus' group (Microphallus piriformes, $M$. pygmaeus and $M$. pseudopygmaeus) for 27 studied populations of either host (Fig. 5A).

When long-term changes in prevalence of different trematodes were related in populations of either Littorina saxatilis or L. obtusata, significant associations were rarely found. Thus, within L. obtusata population from Korga Island no correlation between prevalence of different trematode species was observed throughout the 16 yr study period (Fig. 5C). In L. saxatilis population from this site, a weak positive correlation between levels of infection by Microphallus piriformes and $M$. pygmaeus was found (Fig. 5C), and this relationship was not statistically significant after applying the sequential Bonferroni correction. In the L. saxatilis population from Rjazhkov Island a weak positive relationship was detected between long-term changes of the infection prevalences of $M$. pygmaeus and immature microphallids of 'pygmaeus' group, and for the pair Renicola sp.-Himasthla sp. (Fig. 5B). The only positive association was found in the $L$. obtusata population from this site, and this was between prevalence of $P$, atomon and Renicola sp. (Fig. 5B). This correlation was significant even when the correction for multiply comparisons was considered.

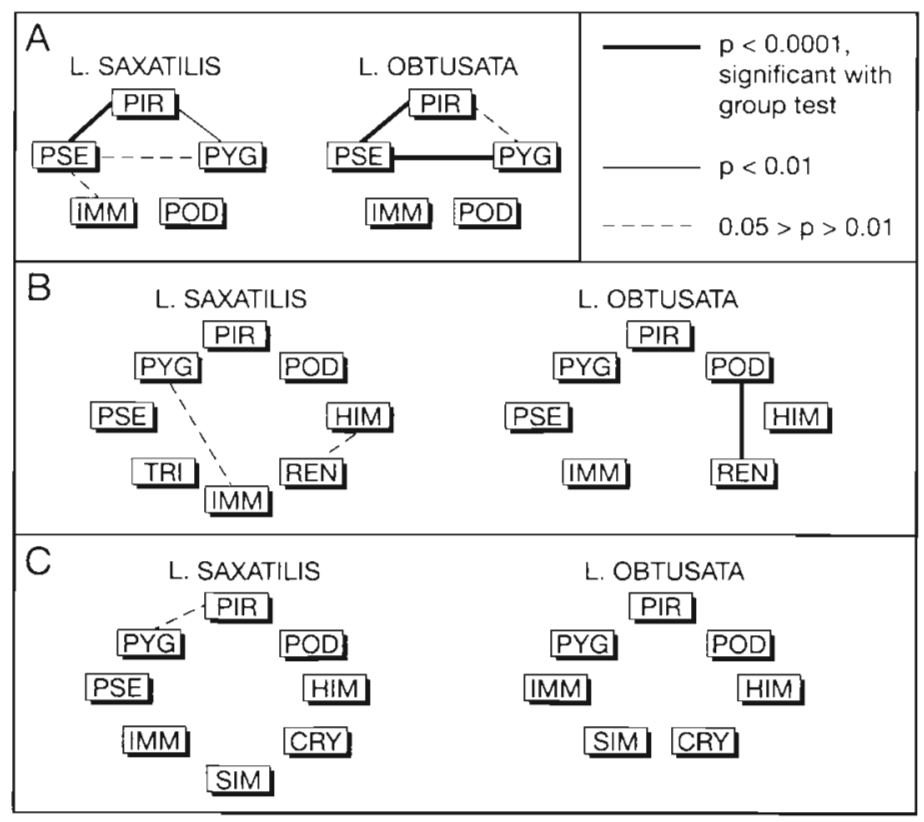

Fig. 5. Correlations of the prevalence of different trematodes in populations of the host species (Littorina saxatilis and L. obtusata). Correlations in (A) 27 populations from spatially separated sites; (B) in the populations from the West Spit of Rjazhkov Island over the $16 \mathrm{yr}$ study period; (C) in the populations from the Korga Island over the 16 yr study period. IMM: immature sporocysts of microphallids. See Table 1 for other species abbreviations 


\section{DISCUSSION}

The species list of trematodes found in the studied populations of Littorina saxatilis and L. obtusata is consistent with those previously reported for White Sea periwinkles (Mikhailova et al. 1988, Granovitch 1992). Trematode infection is common for the White Sea populations of the littorines. However, differences in the infection prevalence between the spatially separated populations of the host species could be large. Considering trematode-induced castration of infected periwinkles (Granovitch 1992, Galaktionov 1993), in some sites, trematodes may exert strong influence upon the host populations. More than half of the adult periwinkle population is excluded from reproduction.

Spatial variation in the trematode prevalence of the periwinkles probably reflects distribution of the definitive hosts. The regions studied are breeding areas for many sea shore-feeding birds which serve as definitive hosts for the trematode species (Table 1). Within each of the 2 regions studied, the sites with increased trematode infection are actively and preferably used by sea birds during feeding and rest (our observations). A similar pattern appears in a larger scale comparison between the 2 regions studied. The North Archipelago region is a protected area of the Kandalaksha nature reserve. In this region, the population density of shore-feeding birds (especially common eiders and sea gulls) is very high (authors' pers. obs.). In contrast, in the Chupa Inlet the population density of the sea birds is much lower. Hence, in the North Archipelago region the levels of infection by the microphallids of the 'pygmaeus' group (which use the common eider Somateria mollissima and sea gulls of the Larus genus as definitive hosts) are significantly higher than in the Chupa Inlet area.

Relative abundance of different trematodes is similar in the 2 host species. The highest prevalence is recorded for the microphallids of the 'pygmaeus' group of which Microphallus piriformes is the most abundant. These parasites have a dixenic life cycle without free-living cercariae. High prevalence was previously reported for these trematodes in the intertidal zone of the sub-Arctic, and in the White, Barents and Norwegian Seas (Granovitch 1992. Galaktionov 1993, Galaktionov \& Bustnes 1995). In contrast, in temperate areas the parasites with trixenic life-cycle and free-living cercariae dominate in the same species of the periwinkles (Werding 1969, Lauckner 1984, 1986). As was suggested by Galaktionov (1993) dixenic, relatively autonomous life cycles, where the only stage that contacts with the environment is an egg, are advantageous under the severe conditions of the intertidal of sub-arctic and arctic seas, hence reducing environmental hazards experienced by the parasites.

The long-term dynamics of trematode infection in the studied populations of periwinkles are mostly governed by changes in the prevalence of microphallids of the 'pygmaeus' group, and mainly of Microphallus piriformes. Despite considerable variation in the prevalence of this parasite during $16 \mathrm{yr}$ of the study, it was consistently the most abundant trematode species in the studied populations of the winkles.

Owing to identical species list of the trematodes found in Littorina saxatilis and L. obtusata, we may quantitatively analyse the concomitant occurrence of a certain trematode in coexisting host populations

Our data suggest that Microphallus piriformes has hugher specificity for Littorina saxatilis than for $\bar{L}$. obtusata. In the 2 populations studied over a 16 yr long period, the prevalence of $M$. piriformes was significantly and consistently higher than in the coexisting population of $L$. obtusata. This suggestion is also supported by 2 kinds of indirect evidence:

(1) The higher prevalence of immature microphallids in Littorina saxatilis from Korga as compared to coexisting $L$. obtusata population could be a reflection of the tendency to the higher specificity of $L$. saxatilis for Microphallus piriformes, as the group of immature microphallids was mostly represented by $M$. piriformes at different stages of development. Similarly, the infection prevalence by immature microphallids tended to be higher in $L$. saxatilis population from the West Spit of Ryazhkov Island, although this trend was not statistically significant.

(2) Although the prevalence of Microphallus piriformes did not significantly differ in the 2 hosts from the spatially separated sites in the North Archipelago and Chupa regions, there was a statistically significant excess of the total infection levels in Littorina saxatilis populations over the coexisting populations of $L$. obtusata. Analysis of the relative abundance of different trematode species showed that, in all the studied populations, most infection was due to $M$. piriformes and immature microphallids. Hence, the higher specificity of $M$. piriformes for $L$. saxatilis is revealed in these populations only if both mature and immature stages of the parasites are taken into account.

In contrast, there was a tendency for higher prevalence of Microphallus pygmaeus in Littorina obtusata populations compared to L. saxatilis. However, this tendency was statistically significant only in Littorina populations from the West spit of the Ryazhkov Island during the 16 yr long study. Generally, a disparate distribution of the closely related trematode species in the populations of the closely related coexisting hosts may suggest specialisation of these parasites in statu nascendi. 
Analysis of co-occurence of the same trematode species in the 2 Littorina spp. showed that infection levels of Microphallus piriformes, M. pygmaeus and M. pseudopygmaeus were significantly correlated in the 2 hosts. This pattern was most clearly revealed by the analysis of the infection prevalence in 27 spatially separated populations of $L$. saxatilis and $L$. obtusata. This probably reflects the distribution of the definitive hosts which are common for these trematodes (Galaktionov 1993) and, consequently, the influx of the trematode eggs into the snail populations. Close coordination between the levels of the infection by these 3 trematode species in $L$. saxatilis and L. obtusata suggests that the parasites' 'flow' through populations of each of the 2 host species is proportional. Among the different trematode species, the closest association was found between the occurrence of $M$. piriformes and $M$. pseudopygmaeus in all host-parasite combinations. Probably, these 2 species share most common features in ecological requirements and conditions of the life cycle.

In contrast to the study of 'spatial' association between the occurrence of trematodes in different host species, analysis of the long-term dynamics of the trematode infection in Littorina populations gives a different insight into the peculiarities of host-parasite interactions at the population level. Correlated longterm dynamics of the infection prevalence in the 2 host species was found for the microphallids of the 'pygmaeus' group (similar to the above-reported spatial association between these trematodes), especially for Microphallus piriformes and immature microphallids. This association was somewhat weaker in the case of $M$. pygmaeus. Probably, the coinciding dynamics of the infection levels in Littorina spp. depends on the synchronous periodical changes in the influx of invasive trematode eggs to the studied populations which may in turn reflect changes in the infection prevalence of the definitive hosts and/or variation in the conditions of infection transfer to the intermediate hosts in different years.

The only case of correlated dynamics of infection prevalence including a non-microphallid trematode was found on the West Spit of Ryazhkov Island: it was a significant correlation between the prevalence of Renicola sp. from Littorina obtusata and Microphallus pseudopygmaeus from $L$. saxatilis. Considering that this feature was found at only 1 site and is not confirmed either by the data on 27 spatially separated populations or by the long-term data on the populations from Korga Island, we suggest that this correlation does not reflect interspecific connections. Probably, this observation results from low (close to zero) values of prevalence by these parasites.
From the viewpoint of the concept of parasitic systems (Beklemishev 1970, Sergievsky et al. 1997), our data suggest that the dynamic of paraxenic flows of parasites through populations of the 2 host species are consistent. This consistency is clearly revealed when the prevalence by Microphallus piriformes, and to a certain extent $M$. pygmaeus, is analysed.

Different microphallid species of the 'pygmaeus' group (Microphallus piriformes, $M$. pygmaeus and M. pseudopygmaeus) demonstrated concordant spatial distribution within each of the 2 host species. At the sites with high infection levels all 3 species have higher prevalence, and vice versa. However, the longterm changes of the infection prevalence on the West spit of Ryazhkov Island and on Korga showed only weak correlations between these 3 parasites. Hence, the dynamics of infection by different trematodes within each host population is largely asynchronous and uncorrelated. Using the concept of the parasitic system we may conclude that the dynamics of different parasitic systems made of by different trematode species and the same host species is rather independent. This is also true for most rarer trematodes with freeliving cercariae.

The question of highly correlated dynamics of Podocotyle atomon and Renicola sp. in Littorina obtusata population (Fig. 6) needs further investigation. The life cycles of the 2 parasites differ greatly. The only common feature of their life cycles is their trixenic mode and use of the periwinkles as first intermediate hosts. Unlike all other trematodes found in the White Sea periwinkles $P$. atomon uses fish as a definitive hosts. Hence, it is difficult to expect that the synchronous dynamics of infection by Renicola sp. and $P$. atomon are governed by the influx of the invasive eggs into the L. obtusata population.

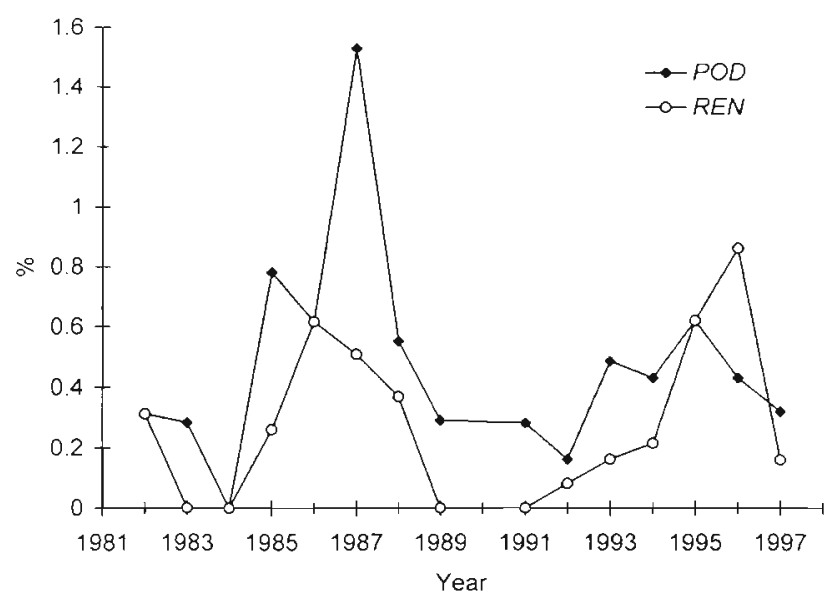

Fig. 6. Long-term dynamics of the prevalence of Podocotyle atomon (POD) and Renicola sp. (REN) in Littorina obtusata on the West Spit of Rjazhkov Island 
Acknowledgements. The authors are grateful to the administration of the Kandalaksha Nature Reserve and personally to Drs V. Bianki, N. Boiko and A. Koryakin for permission to work in the Reserve and for hospitality during our stay on Rjazhkov Island. We also wish to thank Prof. Dr V. Berger (White Sea Biological Station of Zoological Institute of the Russian Academy of Science) for providing logistic support for our expeditions and all the students who helped us during this long study

\section{LITERATURE CITED}

Abdul-Salam J, Sreelatha BS, Al-Kandari W (1997) Temporal variations in the infection of a population of Clypeomorus bifasciata (Gastropoda: Prosobranchia) by a digenean microphallid larva in Kuwait Bay. J Helminthol 71:1-7

Bakus GJ (1990) Quntitative ecology and marine biology. AA Balkema, Rotterdam

Beklemishev VN (1970) The biocenotical basis of the comparative parasitology. Nauka, Moskow

Bush AO, Lafferty KD, Lotz JM, Shostak AW (1997) Parasitology meets ecology on its own terms: Margolis et al. revised. J Parasitol 83:575-583

Curtis LA (1996) The probability of a marine gastropod being infected by a trematode. J Parasitol 82:830-833

Galaktionov KV (1993) Trematode life cycles as components of ecosystems (an attempt of analysis by example of representatives of family Microphallidae). Kola Scientific Center RAN, Apatity

Galaktionov KV, Bustnes JO (1995) Species composition and prevalence of seabird trematode larvae in periwinkles at two littoral sites in North-Norway. Sarsia 80:187-191

Galaktionov KV, Dobrovolsky AA (1984) The try of population analysis of life cycles of Trematodes by example of 'pygmaeus' type microphallides (Trematoda: Microphallidae). In: Polyansky YuI (eds) Ecological-parasitological investigations of northen seas. Kola Scientific Center AS USSR, Apatity, p 8-41

Galaktionov KV, Dobrovolsky AA (1998) The origin and evolution of trematode life cycles. Nauka, St. Petersburg

Granovitch Al (1992) The effect of trematode infection on the population structure of Littorina saxatilis (Olivi) in the White Sea. In: Graham J, Mill P, Reid DG (eds) Proceedings of the Third International Symposium on Littorinid Biology. The Malacological Society of London, London, p 255-263

Granovitch Al (1996) Parasitare systems and the population structure of parasites. Parasitologıya 30:343-356

Granovitch AI, Mikhailova NA, Sergievsky SO (1987) Age peculiarities of infection of the population of littoral periwinkles Littorina obtusata and L. saxatilis by trematode parthenites. Parasitologiya 21:721-729

Granovitch Al, Sergievsky SO (1990) Assesment of the reproductive structure of mollusc populations Littorina saxatilis
(Olivi) (Gastropoda, Prosobranchia) in the White Sea Zoologicheskii Zhurnal 69:32-41

Janson K (1983) Selection and migration in two distinct phenotypes of Lillorina saxalilis in Sweden. Oecologia 59. $58-61$

Jokela J, Lively CM (1995) Spatial variation in infection by digenetic trematodes in a population of freshwater snails (Potamopyrgus antipodarum). Oecologia 103:509-517

Lafferty K (1993) Effect of parasitic castration on growth, reproduction and population dynamics of the marine snail Cerithidea californica. Mar Ecol Prog Ser 96:229-237

Lauckner G (1983) Diseases of Mollusca: Bivalvia. In: Kinne O (ed) Diseases of marine animals, Vol II. Biologische Anstalt Helgoland, Hamburg, p 477-961

Lauckner G (1984) Impact of trematode parasitism on the fauna of a North Sea tidal flat. Helgol Meeresunters 37: $185-199$

Lauckner G (1986) Ecological effects of larval trematode infestation on littoral marine inverrebrate populations. Int J Parasitol 17:391-398

Matveeva TA (1974) The ecology and life cycles of abundant species of the gastropod molluses of Barents and White Seas. In: Chlebovich $V$ (ed) Investigations of the sea fauna. Nauka, Leningrad, p $65 \cdot 1.90$

Mikhailova NA, Granovitch AI, Sergievsky SO (1.988) Effect of trematodes on the microbiotopiral distribution of molluses Littorina obtusata and L. saxatilis. Parasitologiya 22 $398-407$

Mouritsen KN (1997) Crawling behaviour in the bivalve Macoma balthica: the parasite-manipulation hypothesis revisited Oikos 79:513-520

Raffaelli DG (1982) Recent ecological research on some European species of Littorina. J Molluscan Stud 48:342-354

Reversat J, Silan P (1991) Comparative population biology of digenes and their first intermediate host mollusc: the case of three Helicometra (Trematoda: Opecoelidae) endoparasites of marine prosobranchs (Gastropoda). Ann Parasitol Hum Comp 66:219-225

Rice WR (1989) Analyzing tables of statistical tests. Evolution $43: 223-225$

Rothman KJ (1990) No adjustments are needed for multiple comparisons. Epidemiology 1:43-46

Sergievsky SO, Granovitch AI, Sokolova IM (1997) Long-term studies of Littorina obtusata and Littorina Saxatilis populations in the White Sed. Oceanol Acta 20:259-265

Shostak All: Dick TA (1989) Variability in timing of egg hatch of Triaenophorus crassus Forel (Cestoda: Pseudophyllidea) as a mechanism increasing temporal dispersion of coracidia. Can J Zool 67:1462-1470

Sokal RB, Rohlf FJ (1969) Biometry. The principles and practice of statistics in biological research. WH Freeman \& Company, San Francisco

Werding B (1969) Morphologie, Entwicklung und Ökologie digener Trematoden-Larven der Strandschnecke Littorina Jittorea. Mar Biol 3:306-333

Submitted: November 24, 1999; Accepted: January 7, 2000 Proofs received from author( 4 ): A pril 24, 2000
Editorial responsibility: Albert Sparks,

Seattle, Washington, USA 